\title{
Exploring Critical Factors Affecting Contractors' Coopetition Relationship in International Construction Projects
}

\author{
Lili Gao $\mathbb{D}$, ${ }^{1}$ Xiaopeng Deng $\mathbb{C}^{1},{ }^{1}$ Weimin Yang, ${ }^{2}$ and Tengyuan Chang ${ }^{3}$ \\ ${ }^{1}$ School of Civil Engineering, Southeast University, Nanjing 211189, Jiangsu, China \\ ${ }^{2}$ School of Trade and Logistics, Jiangsu Vocational Institute of Commerce, Nanjing 211100, Jiangsu, China \\ ${ }^{3}$ School of Law, Southeast University, Nanjing 211189, Jiangsu, China \\ Correspondence should be addressed to Xiaopeng Deng; dxp@seu.edu.cn
}

Received 14 May 2020; Revised 9 March 2021; Accepted 26 March 2021; Published 15 April 2021

Academic Editor: Xuemei Liu

Copyright ( 92021 Lili Gao et al. This is an open access article distributed under the Creative Commons Attribution License, which permits unrestricted use, distribution, and reproduction in any medium, provided the original work is properly cited.

\begin{abstract}
Coopetition is a revolutionary mindset that combines competition and cooperation. This paper aims to determine and to explore the critical factors affecting contractors' coopetition relationship (CR) in international construction projects (ICPs). In order to improve CR between international contractors in ICPs, a comprehensive literature review was performed to identify the potential variables affecting the CR. A questionnaire survey of 151 professionals in both academia and industry, which included 53 variables, was conducted to explore the critical factors affecting international contractors' CR in ICPs. Structural equation modeling (SEM) was employed to evaluate the multivariate interrelationships among those variables. As a result, nine underlying factors, including six internal factors and three external factors, were extracted and interpreted. The findings can help international contractors to understand more accurately how the coopetition relationship between contractors is affected and can provide a basis for follow-up research on how to evaluate the coopetition status of contractors and the coopetition strategies adopted in ICPs.
\end{abstract}

\section{Introduction}

It is an important issue for the survival of international contractors, whether to choose competition or cooperation with other contractors in international construction projects (ICPs). The Engineering News Record (ENR) report put forward "It's a Competitive World After All" as the theme in 2013 [1]. Tulacz and Gary [1] considered that, for large contractors, the amount of work is increasing-but so are the demands of their clients and the competition. The ENR report regularly analyzes the current state of the international construction market and recently points out that the current development trend of the international contracting market is relatively optimistic, especially in Asia and North America. With the boom and rapid growth of the market, contractors have the opportunity to develop, but they also face severe competition problems. In a prosperous scene, there are many large international contractors that engage in fierce competition and then lose out. ALPINE BAU, for example, Austria's second-biggest contractor, went bankrupt because of its heavy debt burden. E. PIHL \& SON, Denmark's biggest construction contractor, also went bust because of losses from overbuilding its overseas operations and projects. In this situation, coopetition, which is a revolutionary mindset that combines the concepts of competition and cooperation, is a new chance for international contractors.

This paper provides a balanced relationship between international contractors. Coopetition is a combination of cooperation and competition, which means that two or more competing organizations cooperate to create a bigger business pie and simultaneously compete for bigger pieces [2]. Coopetition creates value through cooperation between competing organizations, aligning different interests toward a common objective and helping to create opportunities for competitive advantage by removing external obstacles and neutralizing threats.

Coopetition strategy is a multidimensional and multifaceted concept that assumes a number of different forms 
and requires multiple levels of analysis. Coopetition encompasses both economic and social issues related to interorganizational interdependence. It implies that organizations can interact in rivalry due to conflicting interests and, at the same time, cooperate due to common interests.

Coopetition could prove critical to the future development of international contractors in international construction projects (ICPs). By helping to coordinate efforts between competing organizations in key areas, it allows them to share competitive advantages and to extend synergy to achieve win-win results. The central and overarching goal is to create mutually beneficial exchanges and added values. In view of the importance of coopetition, our research aims to identify critical coopetition success factors and to prioritize them using factor analysis. Our findings could help organizations practice better coopetition, in turn enhancing competitive advantages.

This paper reports the main findings of the research, which is aimed at exploring the critical factors that affect international contractors' coopetition relationship in ICPs. The paper starts by reviewing previous studies that are related to coopetition research. It then introduces the methodology adopted in this study. Afterward, based on the results of a questionnaire survey, this paper employs exploratory factor analysis and structural equation modeling to classify the key variables identified through the literature review. Then, the nine components are renamed and their connotations analyzed, and the relationships among the underlying factors are discussed. Finally, the conclusions are presented, as well as some issues for further research. The findings can help international contractors to understand more accurately how the coopetition relationship between contractors is affected and can provide a basis for follow-up research on how to evaluate the coopetition status of contractors and the coopetition strategies adopted in ICPs.

\section{Literature Review}

2.1. Defining Coopetition. Cooperation between competitors is not unusual, nor new; it is in fact very common, and it has a long history in business. According to Pekar et al. [3], as early as the 1990s, cooperation agreements between companies were mostly between competitors. The first authors to formalize the term "cooperative competition" were Brandenburger and Nalebuff [2]. They analyzed coopetition with game theory and regarded cooperation as an additive game rather than a zero-sum game. In a zero-sum game, the player (competitor) can win even if the opponent does not lose. This is a prisoner's dilemma variant of game theory [4].

Coopetition is explained in numerous ways with different theoretical frameworks, although always under the same premise that coopetition refers to cooperation with competitors [5]. Coopetition is inherently contradictory (competition and cooperation), so it creates tension. If not handled properly, it is easy to erode and destroy the cooperative and competitive relationship [6]. In fact, according to Bengtsson and Kock [7], the decisive feature of cooperative competition is its contradictory nature. If there is no interaction between the conflict logic of cooperation and competition, coopetition cannot exist [5]. The definition of cooperative competition means to use the relationship of coopetition to solve the problems of competition and cooperation, which are two kinds of opposing logics [8].

Some authors have expanded the definition of coopetition, respectively defining the scope of cooperation and competition. For example, Peng et al. [9] define coopetition as cooperation with competitors in nonmarket areas where direct competition occurs. Bengtsson and Kock [5] gave a similar definition, describing traditional cooperation as a situation where two organizations cooperate in activities such as R\&D or procurement, while competing in activities such as sales [10]. Under these definitions, companies cooperate in areas that do not directly involve customers but compete in areas related to customers [11]. In this case, the motivations for coopetition are organizationally and even physically separate [2].

2.2. Levels of Coopetition Analysis. Previous studies regarding the factors that influence the competition between contractors focused more on the resources, technology, etc. Holt et al. [12] pointed out that a contractor's organizational culture, economic strength, management ability, existing project experience, and past performance are the influencing factors of competition. Kale [13] argued that organizational culture, business relations, competitive strategy, and resources are the main factors of competition between contractors. Dikmen and Birgonul [14] put forward 15 main factors that affect competition, including financial and technical ability. Lu [15] categorized the main factors influencing international contractors' competition into eight types, namely, project management skills, organizational culture, resources, competitive strategy, the relationship between the enterprises, bidding ability, marketing ability, and technical ability. In terms of the influential factors of the international competition of contractors, 98 factors were identified and classified as social influence, technical ability, and so on [16]. These studies have all highlighted some of the main factors that influence contractors' competition in the construction industry.

In recent years, more and more scholars have been studying the factors that influence cooperation in the construction industry. In a study focusing on the factors that influence the construction of successful cooperation, Black [17] concluded that trust, communication, clear responsibility, and consistency are key variables. Cheng [18] pointed out that the support of top management, public communication, coordination, and mutual trust are the four main types of factors in the process of construction cooperation and then analyzed these main factors in the different stages of cooperation. Chan [19] analyzed the key factors that influence construction engineering project cooperation and then put forward conflict resolution strategy formulation and communication, sharing resources, clear responsibilities and obligations, the wishes of the win-win intention, and regular examination as the five main factors. 
At present, the research of coopetition in domestic and foreign academic circles mainly centers on trade enterprises in general industry, and the research content focuses on the study of the coopetition behavior of enterprises. Luo [20] studied the impact of contractual and cooperative relationships on performance in international joint ventures and believed that neither a contractual nor a cooperative relationship could act as a substitute for the other but could rather offer a complementary relationship. A contractual relationship provides an institutional framework for enterprise cooperation, while a cooperative relationship overcomes the limitation of being a pure contract. De Araujo et al. [21] conducted an empirical study on the coopetition relationship and enterprise performance between enterprises and direct competitors, upstream alliance partners, and downstream alliance partners. They took the innovation ability of enterprises as the main index of performance measurement and divided the coopetition relationship into three aspects: the coopetition between direct competitors, the coopetition between enterprises and upstream partners, and the coopetition between enterprises and downstream partners. They also tracked European biotechnology companies for six years and found that competitive strategies can be used not only to manage relationships with direct competitors, but also with upstream and downstream partners. Beersma et al. [22] studied the relationship between competition, cooperation, and performance in a team. In a study of 75 interactive four-person teams, they found that competitive pay arrangements increased team workload and speed, while cooperative pay arrangements improved team accuracy. Teams with extroverted members worked better under cooperative pay arrangements, while teams with more introverted members did better under competitive pay arrangements. The study also found that the arrangement of the pay structure had the greatest impact on the members with low performance. As shown in Table 1, all these identified factors were confirmed by related references.

The existing theories usually regard competition and cooperation as mutually opposite relations, between which conflict occurs, thus weakening the influence of both.

\section{Methods}

3.1. Data Collection. The data collection instrument was a specially designed interview questionnaire comprising openended questions, which allowed the interviewees to share their experiences and opinions without constrained alternatives. The questionnaire consisted of two sections.

Section 1 was designed to collect the general perceptions of coopetition strategy, which included three questions: (1) the work experience that the respondents have, (2) the general level of importance for international contractors implementing coopetition strategy in the international construction market, and (3) in which stages coopetition strategies should be adopted. The respondents were asked to tick, where relevant, more than one appropriate box. In Section 2, respondents were invited to review and indicate the importance of the identified individual variables with the potential to affect the level of coopetition strategy. In a provisional list provided, 53 variables were categorized into four groups, with 15 variables related to management commitment, 16 related to mutual integration and communication management, and 12 related to construction firms' internal variables. Respondents were also encouraged to cite additional variables that were not mentioned in the structured questionnaire according to their experience. Regarding the importance, the respondents were asked to rate the items on a Likert scale of 1-5 (with 1 being the least important, and 5 being the most important). By selecting 1 from the five grades, respondents were then able to provide their views on the degree of importance of each variable to the contribution of coopetition affecting each level separately.

Then, a list of selected experts was developed, and they included (1) 300 international academics who focus on related studies-their personal information was collected from their publications-and (2) 400 practitioners with extensive experience in international project management-drawn from 40 international construction enterprises that were selected from the 2018 top 250 international contractors according to Engineering News Record (ENR). The contact information of the 400 practitioners was collected from the construction management research sector, alumni associations, and the websites of their enterprises.

It should be noted that a brief introduction on coopetition strategy and descriptions of some of the unusual variables were also attached to the questionnaire to ensure that all of the respondents were informed of and were using the same definition/description for each variable.

3.2. Exploratory Factor Analysis (EFA). Exploratory factor analysis has proven to be very useful for identifying the potential relationships between several sets of data and has frequently been employed in studies related to construction management. Exploratory factor analysis is often used to create theories in a new research area, such as the components, correlations, and relative weightings of a list of variables. As part of the analysis, Cronbach alpha reliability was adopted to test the reliability of the 5-point Likert-type scale used for this study. Cronbach's alpha was 0.949 ( $F$ statistic $=15.509$, sig. $=0.000$ ), which is much higher than the 0.70 of Nunnally's guideline [51]. Therefore, all data could be used as a whole for factor analysis.

The majority of the variables included in the questionnaire were used to conduct the factor analysis. A good sample size for factor analysis should be over 100 and five times greater than the number of survey questions [52]. In order to comply with the basic requirements, 30 internal variables (from groups A, B, and C) and 10 external variables (from group D) were selected according to their item-tototal correlations. Various other researchers have also employed a similar procedure to meet the assumptions of factor analysis [53]. As recommended in Field's (2000) study, each variable's communality should be equal to, or more than, 0.40 to have sufficient explanation [54]. Since the variable "employee participation" (A07) had low communality (0.335), it was deleted. Finally, 29 internal variables 
TABLE 1: Summary of the factors that influence the coopetition relationship in previous studies.

\begin{tabular}{|c|c|c|c|c|}
\hline Dimensions & Variables & & Factors & References \\
\hline \multirow{15}{*}{ Management commitment } & \multirow{6}{*}{ Management leadership } & A01 & A clear definition of responsibilities/roles & {$[17,19]$} \\
\hline & & A02 & Support from senior management & [23] \\
\hline & & A03 & Mutually beneficial policy and strategy & [24] \\
\hline & & A04 & Equal power/empowerment & {$[17]$} \\
\hline & & A05 & Maintaining financial liquidity & {$[25,26]$} \\
\hline & & A06 & Organizational motivation & [27] \\
\hline & \multirow{5}{*}{ Organization variables } & A07 & Employee participation & [28] \\
\hline & & A08 & Efficient human resource allocation & {$[7,29]$} \\
\hline & & A09 & Adapting mutual organizational culture & {$[17]$} \\
\hline & & A10 & Dedicated team & {$[23]$} \\
\hline & & A11 & Adapting mutual strength and weakness & [30] \\
\hline & \multirow{4}{*}{ Long-term commitment } & A12 & $\begin{array}{l}\text { Long-term cooperative agreement/ } \\
\text { perspective }\end{array}$ & {$[23,31]$} \\
\hline & & A13 & Commitment to continuous improvement & [17] \\
\hline & & A14 & Periodical evaluation of partnering effect & {$[32]$} \\
\hline & & A15 & Complementary resources & [19] \\
\hline \multirow{16}{*}{$\begin{array}{l}\text { Mutual integration and communication } \\
\text { management }\end{array}$} & \multirow{6}{*}{ Mutual trust } & B01 & Common goal & [33] \\
\hline & & B02 & Commitment to quality & {$[17]$} \\
\hline & & B03 & Fair profit assumption & {$[25]$} \\
\hline & & B04 & Partnering goals' achievement & [23] \\
\hline & & B05 & A commitment to a win-win attitude & [19] \\
\hline & & B06 & Acting consistently with objectives & [17] \\
\hline & \multirow{5}{*}{$\begin{array}{l}\text { Knowledge and risk } \\
\text { sharing }\end{array}$} & B07 & Independent intellectual property & {$[34]$} \\
\hline & & B08 & Effective independent intellectual sharing & {$[35]$} \\
\hline & & B09 & The ability to respond to risks & {$[17,36]$} \\
\hline & & $\mathrm{B} 10$ & Effective risk sharing & [37] \\
\hline & & B11 & High-level data interchange & {$[38]$} \\
\hline & \multirow[t]{2}{*}{ Information support } & $\mathrm{B} 12$ & Effective coordination & [33] \\
\hline & & $\mathrm{B} 13$ & A willingness to share information & [13] \\
\hline & \multirow{3}{*}{$\begin{array}{l}\text { Conflict management } \\
\text { system }\end{array}$} & B14 & Conflict identification & [19] \\
\hline & & B15 & Productive conflict resolution & {$[19,30]$} \\
\hline & & $\mathrm{B} 16$ & Conflict monitoring and improvement & [39] \\
\hline \multirow{12}{*}{ Internal variables } & \multirow{4}{*}{ Technology and resources } & $\mathrm{C} 01$ & Adequate resources & [18] \\
\hline & & $\mathrm{C} 02$ & Extent of natural resource/power seeking & [25] \\
\hline & & $\mathrm{C} 03$ & Technical expertise & {$[40]$} \\
\hline & & $\mathrm{C} 04$ & Technology and innovation & [41] \\
\hline & \multirow{5}{*}{ Corporate influence } & $\mathrm{C} 05$ & Company image and knowledge of brand & {$[42]$} \\
\hline & & $\mathrm{C} 06$ & Advertising and promotion of company & {$[42]$} \\
\hline & & $\mathrm{C} 07$ & Strong relationship with governments & {$[43]$} \\
\hline & & $\mathrm{C} 08$ & Firm's degree of internationalization & {$[44]$} \\
\hline & & C09 & Degree of localization & {$[41,45]$} \\
\hline & \multirow{3}{*}{ Firm's capability } & $\mathrm{C} 10$ & Previous work experience & {$[12,23]$} \\
\hline & & $\mathrm{C} 11$ & Marketing capability & {$[15]$} \\
\hline & & $\mathrm{C} 12$ & Project management skills & {$[12]$} \\
\hline \multirow{10}{*}{ External variables } & \multirow{3}{*}{ Political environment } & D01 & $\begin{array}{c}\text { Degree of stability of the government/ } \\
\text { regime }\end{array}$ & [46] \\
\hline & & D02 & Policy uncertainty & {$[46]$} \\
\hline & & D03 & $\begin{array}{l}\text { Attitude toward the project by the host } \\
\text { country }\end{array}$ & {$[46]$} \\
\hline & \multirow{3}{*}{ Industry variables } & D04 & Level of industry competition & [47] \\
\hline & & D05 & Degree of industry concentration & [48] \\
\hline & & D06 & Level of industry maturity & {$[45]$} \\
\hline & \multirow{4}{*}{ Economic performance } & D07 & Currency instability & {$[41]$} \\
\hline & & D08 & Inflation & [49] \\
\hline & & D09 & Exchange rate volatility & [41] \\
\hline & & D10 & Credit ratings & {$[50]$} \\
\hline
\end{tabular}


and 10 external variables were analyzed separately. As the current research sample comprised 151 respondents, this yielded a ratio of variables to sample size as $1: 5$ and $1: 15$ for the macro- and microvariables, respectively, which indicated that it is useful and sufficient to use factor analysis.

The factorability of the item correlation matrix was tested by using the Kaiser-Meyer-Olkin (KMO) index $(\mathrm{KMO} \geq 0.50)$ [55] and Bartlett's test $(p<0.05)$ [56]. The optimal number of factors was determined by sequentially using latent root criteria (eigenvalues $>1.0$ ). Orthogonal (Varimax) rotation was employed in this study. To increase the correlation, each factor retained items with loadings $\geq 0.40$ [57]. Factor internal consistency was determined using two methods: Cronbach's $\alpha \geq 0.70^{16}$ and item-to-total correlations $\geq 0.40$ [58].

3.3. Structural Equation Modeling (SEM). Confirmatory factor analysis is a reliable tool to check a theoretical model based on first-hand data from the questionnaires [59]. In this study, confirmatory factor analysis was conducted based on structural equation modeling (SEM) theory. SEM is a combination of multiple regressions, path analysis, factor analysis, and covariance analysis and is widely used to explore unobservable latent constructs of the causality model in social research [60]. Compared with multiple regression and neural network methods, SEM has the advantages of (1) estimating multiple and interrelated dependence relationships, (2) representing unobserved concepts in these relationships, (3) considering measurement errors in estimates, and (4) defining a model explaining an entire set of relationships. The commonly used SEM has two types, namely, covariance-based SEM (CB-SEM) and partial least squares SEM (PLS-SEM). Compared to PLS-SEM, CB-SEM has been observed to be more suitable for analyzing complex models, especially when the sample size is large enough [61]. In this research, 151 questionnaires were used to examine 29 internal items and 10 external items, respectively, five times and fifteen times the number of observed variables, meaning that the sample size is enough to meet the requirements of CB-SEM analysis. This paper mainly used Amos 21.0 software to model, analyze, and process the contents to be studied, and to discover the relationship between various variables. The establishment of a structural equation model has five main steps: (1) model specification, (2) model identification, (3) model estimation, (4) model evaluation, and (5) model modification.

According to previous studies, $\chi^{2} / \mathrm{d} f$ is a statistic that directly tests the similarity between the sample covariance matrix and the estimated total covariance matrix. The theoretical expectation of $\chi^{2} / \mathrm{d} f$ is 1 , and the closer $\chi^{2} / \mathrm{d} f$ to 1 , the greater the similarity between the sample covariance matrix and the estimated total covariance matrix, and the better the fitting degree of the model. In the current study, when $\chi^{2} / \mathrm{d} f<3$, the fitting degree of the model was considered to be better. Furthermore, the closer the GFI (Goodness of Fit Index), CFI (Comparative Fit Index), and IFI (Incremental Fit Index) values are to 1 , the better the model fitting is. Generally, as long as the value of these indexes is greater than 0.9 , the model fitting is better. In addition, the closer PNFI (Parsimony Normed Fit Index) and PGFI (Parsimony Fit Index) are to 1, the better the model fitting is. Generally, as long as the values of these indexes are greater than 0.5 , the model fitting is considered to be better. As for RMSEA (Root Mean Square Error of Approximation), the smaller its value, the better the model fitting. When the RMSEA value is less than 0.08 , it indicates that the model fitting is ideal, and a model with less than 0.1 is acceptable. In this paper, $\chi^{2} / \mathrm{d} f$, GFI, RMSEA, PNFI, PGFI, CFI, and IFI were selected as the fitting indexes. The numerical ranges and ideal values of each index are shown in Table 2.

\section{Results}

4.1. Descriptive Statistics. The questionnaire was used to conduct empirical research on domestic and foreign scholars studying international project management, as well as practitioners engaged in international contracting business. The questionnaire survey lasted for three months, in which time 624 questionnaires were issued and 157 questionnaires were collected, among which 151 were valid. Of the 151 valid questionnaires, 66 were from academics from 39 research institutions (including universities) in 13 countries, and 85 were from practitioners from international contractors in China. Of the respondents, $45.7 \%$ had more than 10 years of professional or academic experience in international engineering (see Table 3), and $70.20 \%$ had the opinion that implementing coopetition strategy in international construction market was extremely important for international constructors (see Table 4). Both the academics and practitioners had the same opinion regarding the general level of importance.

Data entry was carried out for 151 effective questionnaires recovered, and SPSS 22.0 was used to analyze the data. The first stage of the analysis was mainly to identify the factors that have a potential important influence on the international contractors' CR in ICPs through mean analysis. Among all 53 potential variables, the mean distribution ranged from 3.31 to 4.49 , indicating that all of the factors summarized in the literature review have a relatively important impact on the research object. The top five were "support from senior management (A02) 4.49," "effective communication (B12) 4.35," "fair profit distribution (B03) 4.34," "mutually beneficial business strategy (A03) 4.32," and "strong win-win will (B05) 4.29."

\subsection{Exploratory Factor Analysis (EFA)}

4.2.1. EFA of the Internal Variables. The 29 internal variables were subjected to factor analysis, with principal component analysis and Varimax rotation. The results in Table 2 clearly depict the KMO index (0.899) and Bartlett's test $\left(\chi^{2}=2108.579, \mathrm{~d} f=406\right.$, sig. $\left.=0.000\right)$, indicating that the sample data were appropriate for factor analysis.

Eigenvalue-one suggested that it was appropriate to extract six factors, which were then subjected to Varimax rotations [62]. This approach has been proved to be effective 
TABLe 2: Commonly used model fitting index.

\begin{tabular}{lccccrr}
\hline & Absolute indices & \multicolumn{2}{c}{ Parsimony indices } & \multicolumn{3}{c}{ Incremental indices } \\
$\chi^{2} / \mathrm{d} f$ & GFI & RMSEA & PNFI & PGFI & CFI & IFI \\
\hline$<3$ & $>0.90$ & $<0.1$ & $>0.5$ & $>0.5$ & $>0.90$ \\
\hline
\end{tabular}

TABLE 3: Questionnaire survey respondents' work experience.

\begin{tabular}{|c|c|c|c|c|c|}
\hline Working experience (in years) & $<5(\%)$ & $6-10(\%)$ & $11-20(\%)$ & $16-20(\%)$ & $>20(\%)$ \\
\hline Academics & 12.12 & 10.61 & 27.27 & 24.24 & 25.76 \\
\hline Practitioners & 32.94 & 45.88 & 17.65 & 3.53 & 0.00 \\
\hline Total & 23.84 & 30.46 & 21.85 & 12.58 & 11.26 \\
\hline
\end{tabular}

TABLE 4: Importance of the influence of coopetition on international contractors.

\begin{tabular}{lccc}
\hline Respondents & General level of importance & Number of usable responses & Percentage (\%) \\
\hline \multirow{3}{*}{ Academics } & Moderate & 8 & 12.12 \\
& Significant & 5 & 7.58 \\
& Extremely important & 53 & 80.30 \\
\hline \multirow{2}{*}{ Practitioners } & Minor & 3 & 3.53 \\
& Moderate & 2 & 2.35 \\
& Significant & 27 & 31.76 \\
\hline Total & Extremely important & 53 & 62.35 \\
\hline
\end{tabular}

in the research of defining key factors [46]. As shown in Table 5, the six-factor solution explained $61.21 \%$ of the variance, which is higher than the $60 \%$ of Malhotra's (2002) guideline [63]. All of the communality values (range $=0.473-0.734$ ) and the corrected item-total correlations (range $=0.479-0.650$ ) signify the reliability of the model. The Cronbach alpha values for the final six factors ranged from 0.729 to 0.826 . The first three factors showed acceptable consistency as they were greater than 0.80 , and the last three factors had lower alpha values that were greater than 0.70 . Nunnally (1978) suggested an alpha score of 0.7 ; therefore, each extracted factor was shown to be internally consistent and reliable [51].

Renaming the factors may provide a better understanding of them in further discussion. The realistic meaning of a factor can be synthesized by combining those variables which have relatively high factor loadings on it. Convergent insights of competition and cooperation theory were applied to interpret the underlying factors as more meaningful and informative, as well as competitive theory, resource-based theory, and value-based theory. The six factors and their associated variables were renamed, respectively, as alliance stability capability (ASC), technological innovation capability (TIC), risk management capability (RMC), effective cooperation capability (ECC), operation and executive capability (OEC), and alliance organization capability (AOC). The associated explanations of these factors are as follows.

4.2.2. EFA of the External Variables. Rotated principal components analysis was performed on the 10 external variables (Table 6). The KMO index (0.761) and Bartlett's test $\left(\chi^{2}=592.107, \mathrm{~d} f=45\right.$, sig. $\left.=0.000\right)$ showed that the variables passed all of the tests required for factor analysis.
According to latent root criterion, three components were extracted through factor analysis, with a cumulative value of up to $67.94 \%$, as shown in Table 6. Each of the variables weighed heavily on only one of the factors, and the loading on each factor exceeded 0.50 . The communality values for the variables extracted within three factors were all well above the 0.50 level. Cronbach's alpha values (range $=0.715-0.855$ ) and the item-to-total correlations (range $=0.382-0.655$ ) indicate that each extracted factor was internally consistent.

Further discussion requires renaming the factors. Based on an examination of the inherent relationships among the variables in each of the factors, the three extracted factors and the associated variables were labeled political environment (PE), industry specifics (IS), and economic performance category (EP). The constituent variables of each of the three components extracted are explained below.

\subsection{Structural Equation Modeling (SEM)}

4.3.1. SEM of the Internal Variables. According to the results of the EFA in Section 4.2.1, there are mainly six types of internal factors affecting international contractors' contesting relationship, and each factor contains multiple indicators. This paper establishes a theoretical model by utilizing AMOS software and using path diagrams to verify the validity of the internal factors affecting the contesting relationship between international contractors. Firstly, a theoretical model was established on the basis of the EFA, as shown in Figure 1.

According to the AMOS output model, the modified index (MI) (Table 6) was used to adjust the SEM of the internal factors that affect the CR between international 
TABLE 5: Results of the factor analysis for the internal variables.

\begin{tabular}{|c|c|c|c|c|c|c|c|c|}
\hline \multirow{2}{*}{ Variables } & \multirow{2}{*}{ Communalities } & \multirow{2}{*}{ Item-total correlation } & \multicolumn{6}{|c|}{ Components (variable grouping) } \\
\hline & & & 1 & 2 & 3 & 4 & 5 & 6 \\
\hline B12 & 0.687 & 0.557 & 0.705 & & & & & \\
\hline B04 & 0.640 & 0.590 & 0.676 & & & & & \\
\hline B13 & 0.503 & 0.490 & 0.653 & & & & & \\
\hline B06 & 0.575 & 0.572 & 0.605 & & & & & \\
\hline A02 & 0.556 & 0.482 & 0.541 & & & & & \\
\hline $\mathrm{C} 10$ & 0.653 & 0.511 & 0.504 & & & & & \\
\hline B05 & 0.565 & 0.570 & 0.492 & & & & & \\
\hline $\mathrm{C} 04$ & 0.728 & 0.579 & & 0.682 & & & & \\
\hline $\mathrm{C} 02$ & 0.649 & 0.492 & & 0.673 & & & & \\
\hline $\mathrm{C} 03$ & 0.669 & 0.611 & & 0.616 & & & & \\
\hline B07 & 0.531 & 0.514 & & 0.597 & & & & \\
\hline B02 & 0.620 & 0.609 & & 0.505 & & & & \\
\hline B11 & 0.530 & 0.605 & & 0.487 & & & & \\
\hline B14 & 0.662 & 0.613 & & & 0.692 & & & \\
\hline B09 & 0.604 & 0.540 & & & 0.670 & & & \\
\hline B16 & 0.706 & 0.540 & & & 0.659 & & & \\
\hline B15 & 0.566 & 0.650 & & & 0.452 & & & \\
\hline A12 & 0.664 & 0.492 & & & & 0.694 & & \\
\hline A13 & 0.691 & 0.628 & & & & 0.673 & & \\
\hline A14 & 0.651 & 0.638 & & & & 0.585 & & \\
\hline B03 & 0.575 & 0.590 & & & & 0.546 & & \\
\hline $\mathrm{C} 12$ & 0.734 & 0.595 & & & & & 0.742 & \\
\hline A01 & 0.684 & 0.516 & & & & & 0.669 & \\
\hline $\mathrm{C} 11$ & 0.510 & 0.516 & & & & & 0.526 & \\
\hline B10 & 0.473 & 0.563 & & & & & 0.466 & \\
\hline A09 & 0.558 & 0.479 & & & & & & 0.661 \\
\hline A04 & 0.552 & 0.541 & & & & & & 0.565 \\
\hline B01 & 0.632 & 0.561 & & & & & & 0.549 \\
\hline A03 & 0.582 & 0.591 & & & & & & 0.541 \\
\hline \multicolumn{2}{|c|}{ Cronbach alpha } & & 0.826 & 0.826 & 0.809 & 0.783 & 0.730 & 0.729 \\
\hline \multicolumn{2}{|c|}{ Eigenvalues } & & 10.551 & 1.867 & 1.620 & 1.451 & 1.162 & 1.100 \\
\hline \multicolumn{2}{|c|}{ Variance (\%) } & & 13.233 & 10.587 & 10.155 & 9.817 & 9.265 & 8.150 \\
\hline \multicolumn{2}{|c|}{ Cumulative variance (\%) } & & 13.233 & 23.820 & 33.975 & 43.793 & 53.058 & 61.208 \\
\hline \multicolumn{2}{|c|}{$\begin{array}{l}\text { KMO measure of sampling } \\
\text { adequacy }\end{array}$} & & 0.899 & & & & & \\
\hline \multirow{3}{*}{\multicolumn{2}{|c|}{ Bartlett's test of sphericity }} & Approx. $\chi^{2}$ & 2108.579 & & & & & \\
\hline & & $\mathrm{d} f$ & 406 & & & & & \\
\hline & & Sig. & 0 & & & & & \\
\hline
\end{tabular}

contractors. The result of the model evaluation indicates that if some items are allowed to be correlated in the model, the chi-square value of the model will be greatly reduced, and the fitting between the data and the model will be better.

As suggested in Table 7, a correlation was first established between the items with the largest MI-namely, e13 and e17, e6 and F5, e4 and e12, and e1 and e7-and then the model was reevaluated. The relationship between e13 and e17 is the relationship between in-depth data exchange (B11) and effective conflict resolution solutions (B15). The relationship between e 4 and $\mathrm{e} 12$ is the relationship between the consistency of words and deeds (B06) and the pursuit of product quality (B02). The consistency of words and deeds is a credibility guarantee for the cooperation object to complete the project according to the quality. The relationship between e1 and e7 is the relationship between effective communication (B12) and strong win-win intention (B05). Regular communication plays a certain role in supervising the formation of the intentions of both parties. The relationship between e18 and F3 is not established here, because the modification of the model should have theoretical significance at the same time, and the perfection of the model should not be blindly pursued without its practical significance. The long-term cooperation agreement (A12, e18) is not related to risk management capability (F3) in theory or in practice; thus the model is not modified. However, existing project experience (C10, e6) and operation and execution ability (F5) can be linked; the enterprise's project experience has a great influence on the enterprise's project management ability, and an enterprise's appropriate project management technology can turn the risks in cooperation into opportunities and can promote the success of cooperation [23].

Reevaluate the revised model; the fitting index is shown in Table 8. The ratio of $\chi^{2} / \mathrm{d} f$ is 1.625 , which is less than 3 ; the estimated value of RMSEA is 0.065 , which is less than 0.1 ; GFI is increased from 0.784 to 0.796 , indicating that the model has been improved; the estimated values of PNFI and 
TABLE 6: Results of the factor analysis for external variables.

\begin{tabular}{|c|c|c|c|c|c|}
\hline \multirow{2}{*}{ Variables } & \multirow{2}{*}{ Communalities } & \multirow{2}{*}{ Item-total correlation } & \multicolumn{3}{|c|}{ Components (variable grouping) } \\
\hline & & & 1 & 2 & 3 \\
\hline D02 & 0.749 & 0.477 & 0.846 & & \\
\hline D03 & 0.575 & 0.466 & 0.719 & & \\
\hline D01 & 0.605 & 0.509 & 0.716 & & \\
\hline D06 & 0.721 & 0.451 & & 0.831 & \\
\hline D04 & 0.646 & 0.382 & & 0.756 & \\
\hline D05 & 0.672 & 0.544 & & 0.743 & \\
\hline D09 & 0.767 & 0.594 & & & 0.855 \\
\hline D08 & 0.743 & 0.655 & & & 0.826 \\
\hline D07 & 0.707 & 0.629 & & & 0.802 \\
\hline \multirow[t]{2}{*}{ D10 } & 0.610 & 0.581 & & & 0.714 \\
\hline \multirow{2}{*}{\multicolumn{2}{|c|}{$\begin{array}{l}\text { Cronbach alpha } \\
\text { Eigenvalues }\end{array}$}} & & 0.715 & 0.737 & 0.855 \\
\hline & & & 4.095 & 1.489 & 1.211 \\
\hline \multicolumn{2}{|c|}{ Variance (\%) } & & 28.237 & 19.985 & 19.721 \\
\hline \multicolumn{2}{|c|}{ Cumulative variance (\%) } & & 28.237 & 48.222 & 67.943 \\
\hline \multirow{2}{*}{\multicolumn{2}{|c|}{ KMO measure of sampling adequacy }} & & 0.761 & & \\
\hline & & Approx. $\chi^{2}$ & 592.107 & & \\
\hline \multirow{2}{*}{\multicolumn{2}{|c|}{ Bartlett's test of sphericity }} & $\mathrm{df}$ & 45 & & \\
\hline & & Sig. & 0 & & \\
\hline
\end{tabular}

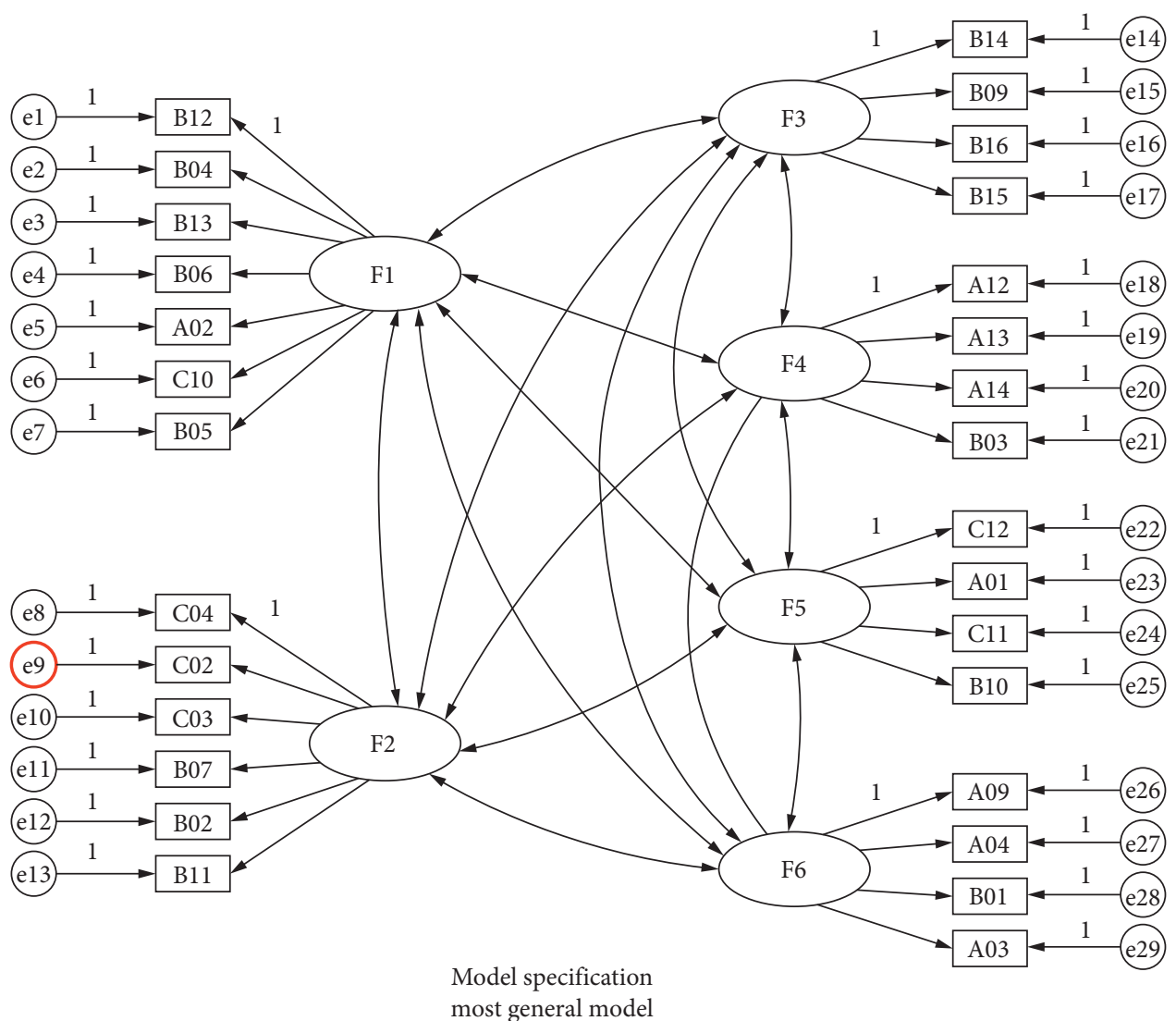

FIgURE 1: Theoretical structural equation modeling (SEM) model of the internal factors.

PGFI are both 0.657 , which is greater than the critical value of 0.5 . In the relative index, the CFI value is 0.879 , and the IFI value is 0.882 , which is less than 0.9 , but in the vicinity of 0.9 , it is slightly lower than the required value. Generally speaking, the adjusted model is better than the theoretical model, and the overall fitting degree of the model is better.

Figure 2 shows the complete standard solution of the SEM of the internal factors in the modified international 
TABle 7: Partial modified index (MI) of the theoretical model of internal factors (only $\mathrm{MI} \geq 6$ ).

\begin{tabular}{llccc}
\hline & & & MI & Par change \\
\hline e18 & $<-->$ & F3 & 12.09207 & -0.11357 \\
e17 & $<-->$ & e29 & 7.21997 & 0.09571 \\
e16 & $<-->$ & F4 & 7.30177 & -0.05831 \\
e16 & $<-->$ & e27 & 9.13414 & 0.10884 \\
e13 & $<-->$ & e17 & 12.91762 & -0.12090 \\
e9 & $<-->$ & F4 & 7.72342 & -0.07795 \\
e8 & $<-->$ & e13 & 7.46768 & -0.10677 \\
e8 & $<-->$ & e10 & 8.38725 & 0.09845 \\
e6 & $<->$ & F5 & 15.08508 & 0.11403 \\
e6 & $<-->$ & e22 & 7.76294 & 0.10032 \\
e5 & $<-->$ & e6 & 8.56138 & 0.10655 \\
e4 & $<-->$ & e12 & 10.90258 & 0.10832 \\
e2 & $<-->$ & F5 & 7.38872 & -0.06798 \\
e1 & $<->$ & e18 & 7.94748 & -0.11614 \\
e1 & $<-->$ & e13 & 7.41260 & 0.09364 \\
e1 & $<-->$ & e7 & 13.49295 & -0.12451 \\
\hline
\end{tabular}

TABle 8: Modified model fitting index of internal factors.

\begin{tabular}{lccccccc}
\hline \multicolumn{3}{c}{ Absolute indices } & \multicolumn{2}{c}{ Parsimony } & \multicolumn{2}{c}{ Incremental } \\
indices & \multicolumn{2}{c}{ indices } \\
$\chi^{2} / \mathrm{d} f$ & GFI & RMSEA & PNFI & PGFI & CFI & IFI \\
\hline 1.62540 & 0.79639 & 0.06457 & 0.65667 & 0.65725 & 0.87937 & 0.88235 \\
$<3$ & $>0.90$ & $<0.1$ & $>0.5$ & $>0.5$ & $>0.90$ & $>0.90$ \\
\hline
\end{tabular}

contractors' coopetition relationship. It can be found that the correlation between the six factors is high, and the eigenvalues are above 0.5 . In the relationship between the two groups with an eigenvalue greater than 0.80 , technology innovation ability (F2) and operation management ability (F5) are most closely correlated, with an eigenvalue of 0.82 , indicating that the technical innovation ability of an international contractor is closely correlated with his project management ability. Secondly, the relationship between the effective cooperation ability (F4) and the organizational ability (F6) alliance (0.81) reflects that the organizational culture and business strategy of the enterprise are closely related to whether or not the enterprise can produce cooperative behavior. Similar corporate culture and mutually beneficial business strategy can promote the cooperation behavior between international contractors.

4.3.2. SEM of the External Variables. According to the results of the EFA in Section 4.2.2, there are mainly three types of external factors that affect international contractors' contesting relationship, and each factor contains multiple indicators. This paper establishes a theoretical model by utilizing AMOS software and using path diagrams to verify the validity of the internal factors that affect the contesting relationship between international contractors. Firstly, a theoretical model was established on the basis of the EFA, as shown in Figure 3.

According to the variance and covariance matrix (or correlation matrix) of the sample data and the theoretical model, confirmatory factor analysis was carried out, and the fitting parameters were estimated and evaluated. The values of the main fitting parameters are shown in Table 9. By analyzing the estimated value of the fitting parameters, it is found that the ratio of $\chi^{2} / \mathrm{d} f$ is 2.726 , which is less than 3 . The estimated RMSEA value is 0.107 , greater than 0.1 but still around 0.1 , thus only slightly higher than the required value. The GFI is 0.905 , which is greater than the critical value of 0.9 . The PNFI is 0.610 , and the PGFI is 0.609 , which are both greater than the critical value of 0.5 . In the relative index, the CFI is 0.902 , and the IFI value is 0.904 , both greater than 0.9 . In general, the overall fitting degree of the model is good; therefore, no further modification was needed.

The complete standard solution of the structural equation model of the external environmental factors in international contractors' coopetition relationship is shown in Figure 4. Firstly, it can be seen that the correlation between the three factors is not as close as that of the internal factors, and the eigenvalues are all around 0.5. The correlation between industry factors (F8), political environment factors (F7), and economic performance factors (F9) is less than 0.5, indicating that the characteristics of the industry itself and the influence of political economy are lower. However, the political environment factor (F7) is closely related to the economic performance factor (F9), which is greater than 0.5 , indicating that the degree of political stability affects economic performance. From the weight of each factor in each type, each index has a high factor load on its factor. Except for the influence of the host country's attitude toward the project (F7) on the political environment being 0.59, the weights of the other factors are above 0.6 , indicating that the relationship between the factors is relatively strong. This shows that these factors have a great influence on the CR of international contractors in international projects.

\section{Discussion}

\subsection{Connotation of Each Component}

5.1.1. Alliance Stability Capability (ASC). The results imply that contractors' alliance stability capability can significantly influence the CR in ICPs. Seven variables were strongly associated with this component, including (1) "effective coordination (B12)," (2) "partnering goals' achievement (B04)," (3) "a willingness to share information (B13)," (4) "acting consistently with objectives (B06)," (5) "previous work experience (A02)," (6) "support from senior management (C10)," and "a commitment to a win-win attitude (B05)." The first type of factor is named alliance stability capability (ASC) according to the factors included within it.

The factors of ASC have a great influence on the stable development of cooperation after competition, at which time international contractors form a cooperative relationship. For example, such indicators as "effective coordination (B12)," "acting consistently with objectives (B06), "a willingness to share information (B13)," and "a commitment to a win-win attitude (B05)" can promote the increase of trust between partners and can contribute to the stability of the alliance. However, "partnering goals' achievement (B04)," "previous work experience (A02)," and "support from senior management (C10)" are three 


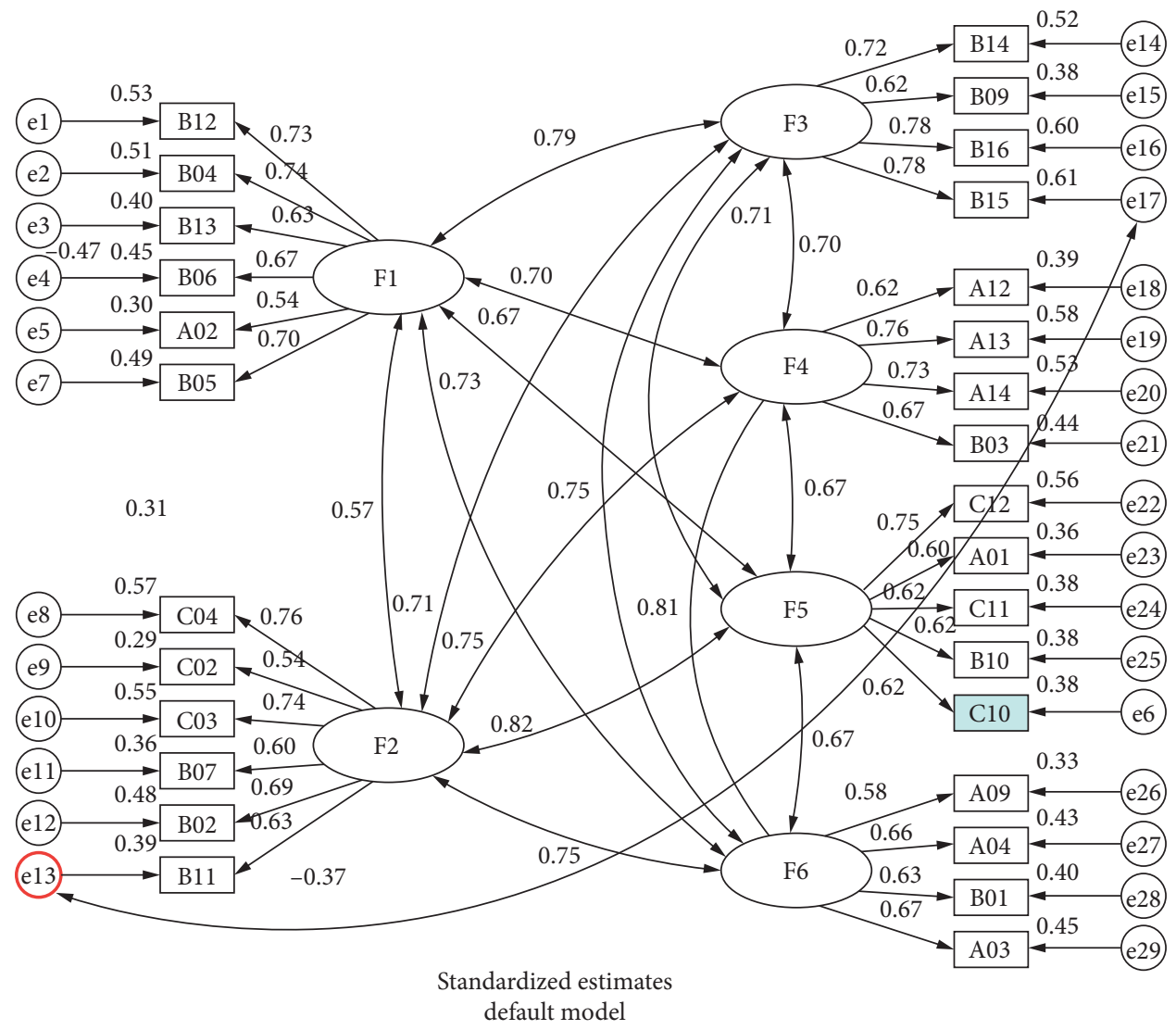

FIgURE 2: Modified SEM results of the internal factors.

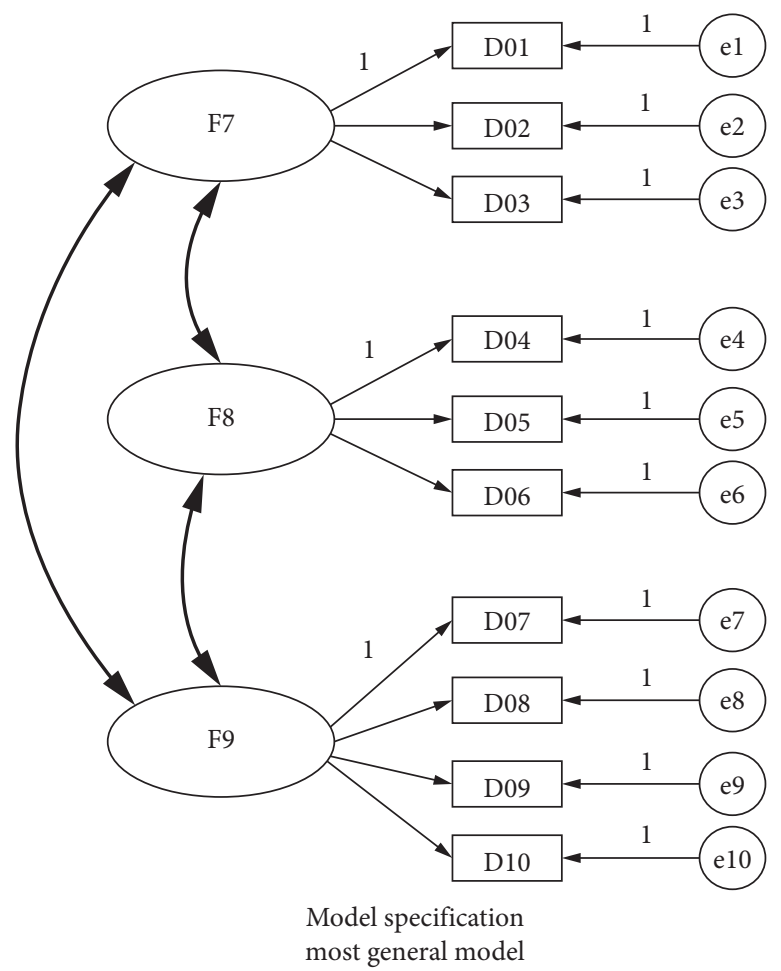

FIGURE 3: Theoretical SEM model of the external factors. 
TABle 9: Model fitting index of the external factors.

\begin{tabular}{lccccccc}
\hline \multicolumn{3}{c}{ Absolute indices } & \multicolumn{2}{c}{ Parsimony } & \multicolumn{2}{c}{ Incremental } \\
indices & \multicolumn{2}{c}{ indices } \\
$\chi^{2} / \mathrm{d} f$ & GFI & RMSEA & PNFI & PGFI & CFI & IFI \\
\hline 2.72617 & 0.90471 & 0.10727 & 0.60925 & 0.52638 & 0.90207 & 0.90427 \\
$<3$ & $>0.90$ & $<0.1$ & $>0.5$ & $>0.5$ & $>0.90$ & $>0.90$ \\
\hline
\end{tabular}

factors that affect the formation of cooperative alliances. Support from senior management is an essential prerequisite for cooperation between previously competing contractors [32]. The alliances of contractors in the construction industry are based on mutual trust, which is the basis of cooperation between competitors. After the original competing contractors form a cooperative relationship or form a competitive alliance, the stability of the alliance directly determines the success or failure of the cooperation and whether or not the cooperation effect can be realized [64]. At the same time, the stable alliance is conducive to enhancing the cooperation confidence and mutual trust among international contractors, which in turn is conducive to the realization of the cooperation goal.

5.1.2. Technological Innovation Capability (TIC). The component "technological innovation capability" accounts for $10.587 \%$ of the total variance. It contains six variables with strong loadings: (1) "technology and innovation (C04)," (2) "extent of natural resource/power seeking (C02)," (3) "technical expertise (C03)," (4) "independent intellectual property (B07)," (5) "commitment to quality (B02)," and (6) "high-level data interchange (B11)."

The intellectual property rights owned by a contractor, the requirements for product quality, and the enterprise's demand for technical resources can all reflect the contractor's technology development level and the enterprise's plan for technology development. This kind of ability is an important index for the evaluation of the contractor's competitiveness. The technical innovation ability determines the contractor's market position in the international project and has a decisive influence on whether or not the international contractor cooperates with competitors [41]. At present, many international engineering projects are technically demanding and difficult to construct, such as nuclear power, high-speed rail, 5G, and other projects. The competitiveness of a contractor in the international engineering market can be greatly enhanced if the contractor has technical innovation capabilities that are not available to other international contractors [65]. When contractors are able to complete technically challenging projects on their own, companies compete more than they cooperate [66]. In this situation, some contractors cooperate with rivals that are willing to invest in or already have new technology to increase the risks.

5.1.3. Risk Management Capability (RMC). Component 3, named as "risk management capability," is responsible for $10.155 \%$ of the total variance of critical variables. According to factor loadings, "conflict identification (B14)," "the ability to respond to risks (B09)," "conflict monitoring and improvement (B37)," and "productive conflict resolution (B15)" were identified among all of the variables.
The international project contracting industry is a highrisk industry; international contractors in overseas projects face great political risk and social conflict [46]. The ability to manage risks and conflicts is also one of the main factors affecting the competitive relationship between international contractors [67]. Many international contractors focus their projects in Africa or the Middle East. The situation in these areas is relatively unstable and there are many social conflicts. International contractors in countries such as Iraq and South Sudan face higher risks. International contractors with strong risk management capabilities can be more competitive in the international engineering market. At the same time, the perfect risk management system can quickly and effectively reduce the loss caused by risks and can solve the problems caused by conflicts. International contractors with strong risk management ability can undertake projects in risky regions by themselves.

5.1.4. Effective Cooperation Capability (ECC). Variables grouped within this factor explain $9.817 \%$ of the total variance. There are four variables involved in this factor: (1) "long-term cooperative agreement/perspective (A12)," (2) "commitment to continuous improvement (A13)," (3) "periodical monitoring of partnering effect (A14)," and (4) "fair profit assumption (B03)."

Long-term commitment is the willingness of the involved parties to integrate continuously to weather unanticipated problems. More committed parties are expected to balance the attainment of short-term objectives with longterm goals and to achieve both individual and joint missions without raising the fear of opportunistic behavior [68, 69]. International contractors chose to cooperate with other competing international contractors; one of the main purposes is to gain more benefit from cooperation, while the effect of such a factor is cooperation, and cooperation can achieve the desired effect. Such a factor is one of the important factors that affects the behavior of cooperation between international contractors; if a long-term cooperation agreement is signed between international contractors to form strategic cooperative relations, the degree of cooperation between the two will be far greater than the level of competition [70].

5.1.5. Operation and Executive Capability (OEC). This principal component, "operation and executive capacity," is responsible for $9.265 \%$ of the total variance, containing a combination of four variables with strong loadings: (1) "project management skills (C12)," (2) "a clear definition of responsibilities/roles (A01)," (3) "marketing capability (C11)," and (4) "effective risk sharing (B10)."

The risk sharing here is mainly for market risks in the process of project execution, such as economic risks, which are different from the political risks and social conflicts of F3. Such factors have an important influence on how international contractors choose to cooperate with their competitors. Operational execution capability is a direct reflection of an international contractor's management capability on the project. In overseas projects, project management is far more complex 
than that in domestic projects. Project managers need to coordinate all aspects of human and material issues. Sometimes, there are sudden situations such as riots of local workers or clashes over cultural differences. Strong project management ability can not only win the favor of the owners more easily in the project bidding but also better guarantee smooth progress of the project [12]. Therefore, excellent project management and execution ability is an important part of the competitiveness of international contractors in ICPs, which affects the change of $\mathrm{CR}$ between international contractors.

5.1.6. Alliance Organization Capability (AOC). This principal component is responsible for $8.150 \%$ of the total variance and contains a combination of four variables with strong loadings: (1) "adapting mutual organizational culture (A09)," (2) "equal power/empowerment (A04)," (3) “common goal (B01)," and (4) "mutually beneficial policy and strategy (A03).”

In the international engineering market, if the two competing international contractors have a similar enterprise organization structure, or their corporate cultures are relatively close to each other, it is more likely to achieve cooperation between the two parties [17]. In terms of forming an alliance between two international contractors, if their organizational cultures are similar, if they have the right to equality and common goals, and if they have mutually beneficial business strategies, then their cooperation will be better, as they will be able to adapt to each other and accept each other, thus fostering effective cooperation. Thus, alliance organization ability has a great influence on the cooperation between international contractors and can promote cooperation among competitors.

5.1.7. Political Environment Category (PEC). Variables grouped within this component are generally related to the political environment, accounting for $28.237 \%$ of the total variance. Three variables have high loadings on this factor: (1) "policy uncertainty (D02)," (2) "attitude toward the project by the host country (D03)," and (3) "degree of stability of the government/regime (D01)."

This factor forms the host country's political variables that influence international contractors in the international engineering market in terms of cooperation with other international contractors; a stable political environment, determining whether or not international contractors engage in overseas projects, is closely related to competition and cooperation [71]. When the political environment is stable, international contractors can compete without doubt or hesitation [72]; however, when the political environment is unstable, they need to engage in more cooperative behavior in order to secure their interests. In ICPs, political risk is the main risk source, and international contractors' concentration in the political environment is more complex; thus, political environment factors have a direct impact on international contractors' coopetition relations.

5.1.8. Industry-Specific Category (ISC). This component is called "industry-specific factor," accounting for $19.985 \%$ of the total variance. It contains a combination of three variables with strong loadings: (1) "level of industry maturity (D06)," (2) "level of industry competition (D04)," and (3) "degree of industry concentration (D05)."

Since each industry has its own competition status, such as transportation, petroleum, buildings, and power, the variables associated with the industry will significantly impact the CR in the international construction industry. When the industry has high maturity, such as in the housing industry, cooperation between international contractors' behavior will be greatly reduced. Housing in terms of international engineering project construction difficulty is low, technical specification is complete, and the experience of international contractors in the industry is rich; therefore, competition is more likely to occur than cooperative behavior. On the other hand, if the industry concentration degree is low, such as petrochemical, nuclear power, highspeed rail, and other industries, international contractors are more likely to engage in cooperative behavior [73]. In regard to the characteristics of the international engineering market, international contractors in each industry are different; thus the industry factors have a bigger influence on Chinese contractors' competitive relations.

5.1.9. Economic Performance Category (EPC). The final component of economic performance contributes to $19.721 \%$ of the total variance. It encompasses four variables, including "exchange rate volatility (D09)," "inflation (D08)," "currency instability (D07)," and "credit ratings (D10)."

The stability of the exchange rate and currency factors affect the size of the risks for international contractors in overseas project and also affect the enterprise strategy decisions of international contractors. Project-host country's exchange rate and monetary and credit ratings can not only reflect the degree of stability of the regional investment environment but also indirectly reflect the local market environment's stability, including its political stability [74]. If the local economy environment is relatively stable, the likelihood of international contractors undertaking the risk of the project will reduce, and the cooperation between international contractors will also be reduced accordingly; on the other hand, if the local economic environment is unstable, the cooperative behaviors of international contractors will increase accordingly.

5.2. Relationships among the Underlying Factors. As mentioned before, coopetition is a combination of competition and cooperation. According to the analysis of nine types of internal and external factors, the internal factors affect both competition and cooperation and thus are external environmental factors. As shown in Figure 5, among the six internal variables that affect CR, "alliance stability capability (ASC)," "effective cooperation capability (ECC)," and "alliance organization capability (AOC)" have a more significant impact on the cooperative relationship, while "technological innovation capability (TIC)," "risk management capability (RMC)," and "operation and executive capability (OEC)" have a more obvious impact on the competitive relationship. As for the external variables, 


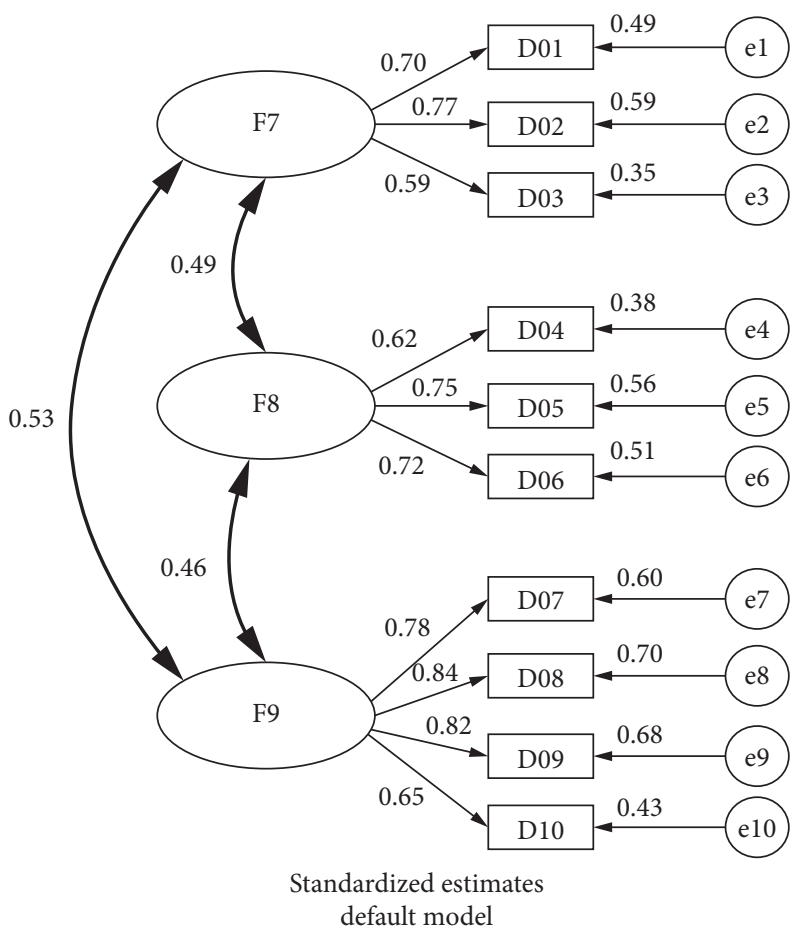

FIGURE 4: SEM results of the external factors.

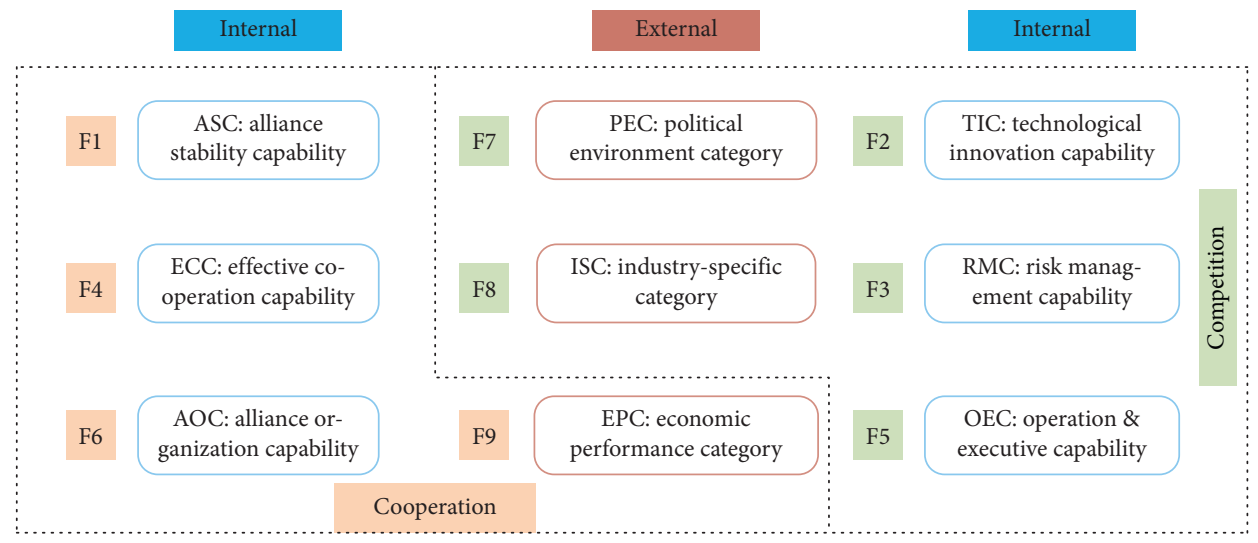

FIGURE 5: Diagram showing the relationships among the underlying factors.

"political environment category (PEC)" and "industryspecific category (ISC)" have a more significant impact on the cooperative relationship, while "economic performance category (EPC)" is a critical factor that affects the cooperative relationship. The influence of internal factors and external factors on competition and cooperation is a complex relationship of cross fusion [20]. These findings provide a theoretical basis for constructing an evaluation model of the coopetition situation for international contractors in ICPs.

\section{Conclusion}

This paper provides an overview of the large number of studies that tried to identify the critical variables that influence international contractors' CR in ICPs. Fifty-three variables with the potential to affect the CR in ICPs were initially identified and surveyed for their significance through questionnaires. It is neither practical nor necessary to manage all related variables to minimize their influence on CR; SEM was thus used to determine the principal variable groupings that underlie the CR.

By means of SEM, a factor structure was identified, which consists of (1) six internal factors: "alliance stability capability (ASC)," "technological innovation capability (TIC)," "risk management capability (RMC)," "effective cooperation capability (ECC)," "operation and executive capability (OEC)," and "alliance organization capability (AOC)"; and (2) three external factors: "political environment category (PEC)," "industry-specific category (ISC)," and "economic performance category (EPC)." The nine factor groupings therefore represent the basic elements of 
variables affecting the CR of international contractors in ICPs and should always be considered by international contractors when managing their projects. The nine underlying factors derived from the critical variables can provide a comprehensive understanding and a possibility to evaluate the coopetition situation for international projects.

These findings have three practical implications. Firstly, endogenous factors (including ASC, TIC, RMC, ECC, OEC, and $\mathrm{AOC}$ ) prove to be the main cause of coopetition relationship behaviors at the internal level. Secondly, at the external level, the political environment is an important determinant of coopetition relationship behaviors. Finally, this paper classified nine kinds of influencing factors from another two dimensions of competition and cooperation and thus provides a basis for constructing a multidimensional evaluation model of contesting state.

This article also has two theoretical values. First, it has enriched the application of coopetition theory to construction enterprises, especially for international contractors, although the coopetition theory has been studied in other business enterprises for some time. Secondly, it provides a theoretical framework and research basis for the subsequent quantitative analysis of the coopetition situation of international contractors.

Further studies will need to be carried out to identify the relations among these factors and to develop a practical evaluation model for the coopetition situation of international projects.

\section{Data Availability}

The data generated and analyzed during the study are available from the corresponding author by request.

\section{Conflicts of Interest}

The authors declare no conflicts of interest.

\section{Acknowledgments}

The authors thank the respondents from both the industry and academia who contributed and assisted by completing the survey questionnaires used in our study of CR in ICPs. The research was funded by the National Natural Science Foundation of China (Grant no. 71771052 and no. 71372199) and University Philosophy and Social Science Project of Jiangsu (Grant no. 2019SJA1777).

\section{References}

[1] Tulacz and Gary, The Top 250 International Contractors, Engineering News Record, New York, NY, USA, 2013.

[2] A. Brandenburger and B. Nalebuff, Coopetition: A Revolutionary Mindset that Combines Competition and Cooperation in the Marketplace, Harvard Business School Press, Brighton, MA, USA, 1996.

[3] P. Pekar and J. R. Harbison, Smart Alliances: A Practical Guide to Repeatable Success, Jossey-Bass, San Francisco, CA, USA, 1998.
[4] A. A. Lado, N. G. Boyd, and S. C. Hanlon, "Competition, cooperation, and the search for economic rents: a syncretic model," Academy of Management Review, vol. 22, 1997.

[5] M. Bengtsson and S. Kock, "“Coopetition" in business networks-to cooperate and compete simultaneously," Industrial Marketing Management, vol. 29, no. 5, pp. 411-426, 2000.

[6] M. M. Wilhelm, "Managing coopetition through horizontal supply chain relations: linking dyadic and network levels of analysis," Journal of Operations Management, vol. 29, no. 7-8, pp. 663-676, 2011.

[7] M. Bengtsson, S. Kock, E.-L. Lundgren-Henriksson, and M. H. Näsholm, "Coopetition research in theory and practice: growing new theoretical, empirical, and methodological domains," Industrial Marketing Management, vol. 57, pp. 4-11, 2016.

[8] M.-J. Chen, "Reconceptualizing the competition- cooperation relationship," Journal of Management Inquiry, vol. 17, no. 4, pp. 288-304, 2008.

[9] T. U. Peng, J. C. Yang, and G. Roos, "Is cooperation with competitors a good idea? an example in practice," British Journal of Management, vol. 23, no. 4, pp. 532-560, 2012.

[10] J. Dahl, "Conceptualizing coopetition as a process: an outline of change in cooperative and competitive interactions," Industrial Marketing Management, vol. 43, no. 2, pp. 272-279, 2014.

[11] R. B. Bouncken, J. Gast, S. Kraus, and M. Bogers, "Coopetition: a systematic review, synthesis, and future research directions," Review of Managerial Science, vol. 9, no. 3, pp. 577-601, 2015.

[12] G. D. Holt, P. O. Olomolaiye, and F. C. Harris, "A review of contractor selection practice in the U.K. construction industry," Building Environment, vol. 30, 1995.

[13] S. Kale, Competitive Advantage in the Construction Industry: Firm-specific Resources and Strategy, Illinois Institute of Technology, Chicago, IL, USA, 1999.

[14] I. Dikmen and M. T. Birgonul, "Strategic perspective of Turkish construction companies," Journal of Management in Engineering, vol. 19, no. 1, pp. 33-40, 2003.

[15] W. Lu, L. Shen, and M. C. Yam, "Critical success factors for competitiveness of contractors: China study," Journal of Construction Engineering and Management, vol. 134, no. 12, pp. 972-982, 2008.

[16] L. Y. Shen, W. Lu, Q. Shen, and H. Li, "A computer-aided decision support system for assessing a contractor's competitiveness," Automation in Construction, vol. 12, no. 5, pp. 577-587, 2003.

[17] C. Black, A. Akintoye, and E. Fitzgerald, "An analysis of success factors and benefits of partnering in construction," International Journal of Project Management, vol. 18, no. 6, pp. 423-434, 2000.

[18] E. W. L. Cheng and H. Li, "Construction partnering process and associated critical success factors: quantitative investigation," Journal of Management in Engineering, vol. 18, no. 4, pp. 194-202, 2002.

[19] A. P. C. Chan, D. W. M. Chan, Y. H. Chiang, B. S. Tang, E. H. W. Chan, and K. S. K. Ho, "Exploring critical success factors for partnering in construction projects," Journal of Construction Engineering and Management, vol. 130, no. 2, pp. 188-198, 2004.

[20] Y. Luo, "A coopetition perspective of MNC-host government relations," Journal of International Management, vol. 10, no. 4, pp. 431-451, 2004.

[21] D. De Araujo and M. Franco, "Trust-building mechanisms in a coopetition relationship: a case study design," International 
Journal of Organizational Analysis, vol. 25, no. 3, pp. 378-394, 2017.

[22] B. Beersma, "Cooperation, competition, and team performance: towards a contingency approach," Australian Journal of Psychology, vol. 55, p. 115, 2003.

[23] E. W. L. Cheng, H. Li, and P. E. D. Love, "Establishment of critical success factors for construction partnering," Journal of Management in Engineering, vol. 16, no. 2, pp. 84-92, 2000.

[24] A. L. Borders, W. J. Johnston, and E. E. Rigdon, "Beyond the dyad: electronic commerce CMD network perspectives in industrial marketing management," Industrial Marketing Management, vol. 30, no. 2, pp. 199-205, 2001.

[25] S. Kale, A. Karihaloo, P. R. Clark, M. Kashgarian, D. S. Krause, and L. G. Cantley, "Bone marrow stem cells contribute to repair of the ischemically injured renal tubule," Journal of Clinical Investigation, vol. 112, no. 1, pp. 42-49, 2003.

[26] A. Gasior, "Financial liquidity analysis of CSR based capital group Zywiec SA," Amfiteatru Economic, vol. 15, p. 784, 2013.

[27] A. G. Hanafi and M. N. M. Nawi, "Critical success factors for competitiveness of construction companies: a critical review," in Proceedings of the International Conference on Applied Science and Technology 2016, F. A. A. Nifa, M. N. M. Nawi, and A. Hussain, Eds., , Kedah, Malaysia, April 2016.

[28] B. Esmaeili, E. Pellicer, and K. R. Molenaar, "Critical success factors for construction projects," in Project Management and Engineering Research, 2014, J. L. A. Munoz, J. L. Y. Blanco, and S. F. CapuzRizo, Eds., Springer, Berlin, Germany, 2016.

[29] D. J. Ketchen, C. C. Snow, and V. L. Hoover, "Research on competitive dynamics: recent accomplishments and future challenges," Journal of Management, vol. 30, no. 6, pp. 779-804, 2004.

[30] M. Zineldin, "Co-opetition: the organisation of the future," Marketing Intelligence \& Planning, vol. 22, no. 7, pp. 780-790, 2004.

[31] W. Czakon, M. K. Srivastava, F. L. Roy, and D. R. Gnyawali, "Coopetition strategies: critical issues and research directions," Long Range Planning, vol. 53, no. 1, 2020.

[32] E. W. L. Cheng and H. Li, "Development of a practical model of partnering for construction projects," Journal of Construction Engineering and Management, vol. 130, no. 6, pp. 790-798, 2004.

[33] A. Hafezalkotob, "Competition, cooperation, and coopetition of green supply chains under regulations on energy saving levels," Transportation Research Part E: Logistics and Transportation Review, vol. 97, pp. 228-250, 2017.

[34] L. M. M. D. Resende, I. Volski, L. M. Betim, G. D. G. D. Carvalho, R. D. Barros, and F. P. Senger, "Critical success factors in coopetition: evidence on a business network," Industrial Marketing Management, vol. 68, pp. 177187, 2018.

[35] J. Chua, J. J. Chrisman, and L. P. Steier, "Extending the theoretical horizons of family business research," Entrepreneurship: Theory and Practice, vol. 27, no. 4, 2003.

[36] T. Chang, X. Deng, J. Zuo, and J. Yuan, "Political risks in central asian countries: factors and strategies," Journal of Management in Engineering, vol. 34, no. 2, pp. 04017059.104017059.10, 2018.

[37] R. M. Morgan and S. Hunt, "Relationship-based competitive advantage," Journal of Business Research, vol. 46, no. 3, pp. 281-290, 1999.

[38] Y. C. Li and W. S. Lu, "An investigation to the critical success factors (CSFs) for improving contractor competitiveness in Chinese construction market," in Proceedings of the CRIOCM 2005 International Research Symposium on Advancement of
Construction Management and Real Estate, C. F. Wu, Ed., pp. 130-135pp. 130-, Hangzhou, China, November 2005.

[39] E. H. Quik, P. S. Van Dam, and J. L. Kenemans, "Growth hormone and selective attention: a review," Neuroscience \& Biobehavioral Reviews, vol. 34, no. 8, pp. 1137-1143, 2010.

[40] D. Nelkin, "The political impact of technical expertise," Social Studies of Science, vol. 5, no. 1, 1975.

[41] I. Alon and T. T. Herbert, "A stranger in a strange land: micro political risk and the multinational firm," Business Horizons, vol. 52, no. 2, pp. 127-137, 2009.

[42] B. M. Ghodeswar, "Building brand identity in competitive markets: a conceptual model," Journal of Product \& Brand Management, vol. 17, no. 1, pp. 4-12, 2008.

[43] X. Zhao, T. Chang, and B. G. Hwang, "Critical factors influencing business model innovation for sustainable buildings," Sustainability, vol. 10, no. 1, 2018.

[44] K. Ramaswamy, K. G. Kroeck, and W. Renforth, "Measuring the degree of internationalization of a firm: a comment," Journal of International Business Studies, vol. 27, no. 1, pp. 167-177, 1996.

[45] T. Chang, X. Deng, and B.-G. Hwang, "Investigating political risk paths in international high-speed railway projects: the case of Chinese international contractors," Sustainability, vol. 11, no. 15, 2019.

[46] X. Deng and S. P. Low, "Exploring critical variables that affect political risk level in international construction projects: case study from Chinese contractors," Journal of Professional Issues in Engineering Education and Practice, vol. 140, no. 1, 2014.

[47] Q. Zhou, X. Deng, R. Jin et al., “Analyzing the key drivers of contractors' temporary competitive advantage in the competition of international high-speed rail projects," KSCE Journal of Civil Engineering, vol. 23, no. 11, 2019.

[48] K. Łobos and M. Szewczyk, "Distribution of the effects of brewing industry concentration among large and small companies operating on the polish market in 2004-2011 period," JARD, vol. 30, no. 4, pp. 149-159, 2013.

[49] A. Besana, "Economics, competition and coopetition of the Italian private welfare state: a cluster analysis," in Eurasian Economic Perspectives, M. H. Bilgin et al., Ed., pp. 15-31, Springer, Berlin, Germany, 2018.

[50] F. Guan, "Evaluation of the competitiveness of China's commercial banks based on the G-CAMELS evaluation system," Sustainability, vol. 11, no. 6, 2019.

[51] J. Nunnally and I. Bernstein, Psychometric Theory, McGrawHill, New York, NY, USA, 3rd edition, 1994.

[52] R. L. Gorsuch, "Factor analysis," in Handbook of PsychologyLawrence Erlbaum Associates, Hillsdale, NJ, USA, 1983.

[53] J. Wang and H. Yuan, "Factors affecting contractors' risk attitudes in construction projects: case study from China," International Journal of Project Management, vol. 29, no. 2, pp. 209-219, 2011.

[54] A. P. Field, Discovering Statistics using SPSS for Windows: Advanced Techniques for Beginners, Sage Publications, Inc, Thousand Oaks, CA, USA, 2000.

[55] H. F. Kaiser, "The application of electronic computers to factor Analysis," Educational and Psychological Measurement, vol. 20, no. 1, pp. 141-151, 1960.

[56] G. R. Bartlett, "Phosphorus assay in column chromatography," Journal of Biological Chemistry, vol. 234, no. 3, pp. 466-468, 1959.

[57] J. C. Cappelleri, S. E. Althof, R. L. Siegel, A. Shpilsky, S. S. Bell, and S. Duttagupta, "Development and validation of the selfesteem and relationship (SEAR) questionnaire in erectile 
dysfunction," International Journal of Impotence Research, vol. 16, no. 1, pp. 30-38, 2004.

[58] C. H. Park and Y. G. Kim, "Identifying key factors affecting consumer purchase behavior in an online shopping context," International Journal of Retail \& Distribution Management, vol. 31, no. 1, pp. 16-29, 2003.

[59] R. B. Kline, Principles and Practice of Structural Equation Modeling, Guilford Publications, New York, NY, USA, 2015.

[60] T. Chang, X. Deng, J. Zuo, and J. Yuan, "Political risks in central asian countries: factors and strategies," Journal of Management in Engineering, vol. 34, no. 2, 2018.

[61] W. W. Chin and G. Marcoulides, "The partial least squares approach to structural equation modeling," Advances in Hospitality and Leisure, vol. 8, no. 2, 1998.

[62] R. J. Rummel, Applied Factor Analysis, Northwestern University Press, Evanston, IL, USA, 1970.

[63] U. R. Orth, "Marketing research: book review: marketing research: an applied orientation," Australasian Marketing Journal, vol. 10, no. 2, pp. 72-74, 2002.

[64] L. Caricati, G. Moscato, and C. Bonetti, "Intergroup alliance orientation among intermediate-status group members: the role of stability of social stratification," PLos One, vol. 15, no. 7, Article ID e0235931, 2020.

[65] Y. Niu, X. Deng, L. Zhang, and X. Duan, "Understanding critical variables contributing to competitive advantages of international high-speed railway contractors," Journal of Civil Engineering and Management, vol. 25, no. 2, pp. 184-202, 2019.

[66] C. Devece, D. E. Ribeiro-Soriano, and D. Palacios-Marqués, "Coopetition as the new trend in inter-firm alliances: literature review and research patterns," Review of Managerial Science, vol. 13, no. 2, pp. 207-226, 2019.

[67] X. P. Deng, S. P. Low, X. Zhao, and Q. Li, "Developing competitive advantages in political risk management for international construction enterprises," Journal of Construction Engineering and Management, vol. 140, no. 9, 2014.

[68] A. Parkhe, "Strategic alliance structuring: a game theoretic and transaction cost examination of interfirm cooperation," Academy of Management Journal, vol. 36, no. 4, pp. 794-829, 1993.

[69] J. Mohr and R. Spekman, "Characteristics of partnership success: partnership attributes, communication behavior, and conflict resolution techniques," Strategic Management Journal, vol. 15, no. 2, pp. 135-152, 1994.

[70] F. Le Roy and W. Czakon, "Managing coopetition: the missing link between strategy and performance," Industrial Marketing Management, vol. 53, pp. 3-6, 2016.

[71] X. Deng, S. P. Low, X. Zhao, and T. Chang, "Identifying micro variables contributing to political risks in international construction projects," Engineering, Construction and Architectural Management, vol. 25, no. 3, pp. 317-334, 2018.

[72] T. Chang, X. Deng, X. Zhao, and B. G. Hwang, "Political risk paths in international construction projects: case study from Chinese construction enterprises," Advances in Civil Engineering, vol. 2018, Article ID 6939828, , 2018.

[73] N. Zhang, X. Deng, X. Zhao, and T. Chang, "Exploring the sources of contractors' competitive advantage on international HSR construction projects," International Journal of Civil Engineering, vol. 17, no. 7, pp. 1115-1129, 2019.

[74] X. P. Deng and L. S. Pheng, "Understanding the critical variables affecting the level of political risks in international construction projects," KSCE Journal of Civil Engineering, vol. 17, no. 5, pp. 895-907, 2013. 